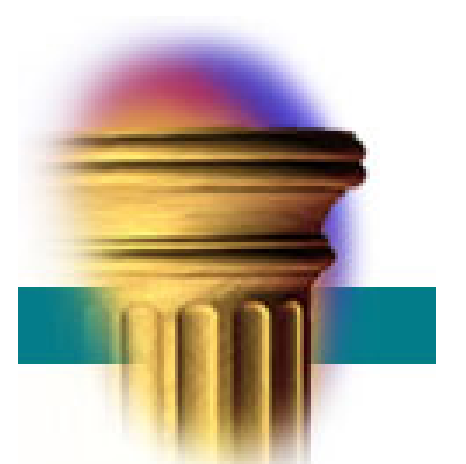

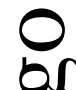 \\ Using the Eye of the Storm to Predict the Wave of Covid-19 UI Claims
}

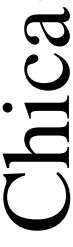

m

\author{
Daniel Aaronson, Scott A. Brave, R. Andrew \\ Butters, Daniel Sacks, and Boyoung Seo
}

\section{REVISED \\ April 16, 2020}

WP 2020-10

https://doi.org/10.21033/wp-2020-10

${ }^{*}$ Working papers are not edited, and all opinions and errors are the responsibility of the author(s). The views expressed do not necessarily reflect the views of the Federal Reserve Bank of Chicago or the Federal Reserve System. 


\title{
Using the Eye of the Storm to Predict the Wave of Covid-19 UI Claims ${ }^{1}$
}

\author{
Daniel Aaronson $\quad$ Scott A. Brave $\quad$ R. Andrew Butters Daniel Sacks Boyoung Seo ${ }^{2}$
}

April 16, 2020

\begin{abstract}
We leverage an event-study research design focused on the seven costliest hurricanes to hit the US mainland since 2004 to identify the elasticity of unemployment insurance filings with respect to search intensity. Applying our elasticity estimate to the state-level Google Trends indexes for the topic "unemployment," we show that out-of-sample forecasts made ahead of the official data releases for March 21 and 28 predicted to a large degree the extent of the Covid-19 related surge in the demand for unemployment insurance. In addition, we provide a robust assessment of the uncertainty surrounding these estimates and demonstrate their use within a broader forecasting framework for US economic activity.
\end{abstract}

JEL Codes: H12, J65, C53

Keyword: unemployment insurance, Google Trends, hurricanes, search, unemployment, Covid-19

${ }^{1}$ The views expressed herein are those of the authors and do not necessarily represent those of the Federal Reserve Bank of Chicago or the Federal Reserve System. The authors thank, without implicating, Timothy Slaper, and the Indiana Department of Workforce Development for helpful conversations, as well as Ross Cole and Michael Fogarty for excellent research assistance.

${ }^{2}$ Economic Research, Federal Reserve Bank of Chicago: daaronson@frbchi.org, sbrave@frbchi.org Business Economics and Public Policy, Kelley School of Business: rabutter@indiana.edu, dansacks@indiana.edu, seob@indiana.edu. 
The advent of private sector "big data" has the potential to substantially alter the landscape of economic statistics and forecasting, as researchers use this data to develop statistical methods that can be used to improve the timing and corroborate the accuracy of official statistics. ${ }^{3}$ One of the most broadly known examples of these new data are the Google Trends indexes, which track search patterns for words or phrases entered into the Google search engine. ${ }^{4}$ We show how to make use of this timely information in order to calibrate the take-up for unemployment insurance (UI). Our key insight is to use the historical experience of US hurricanes. This approach is especially promising because these events generate very large and sharp spatial changes in new UI claims. ${ }^{5}$ We apply this insight to the seven costliest hurricanes to make landfall in the mainland US since 2004 and show that the Google Trends data is highly predictive of subsequent UI take-up. Furthermore, using the same model, we demonstrate that the unprecedented take-up in UI during the first few weeks of the Covid-19 pandemic was largely predicted on the sole basis of Google Trends.

Extreme events, like the Covid-19 pandemic, are difficult to handle for traditional macroeconomic forecasting models that rely on standard sources of economic data that often take weeks, and in some cases months, to be released. Even initial UI claims, one of the rare economic series available at a weekly frequency, has a lag of 5-12 days. But the timeliness of weekly claims makes it an important and commonly used leading indicator of the business cycle. ${ }^{6}$ As such, modern forecasting models that make use of data series observed at mixed frequencies rely heavily on the signal UI claims provides in the real-time data flow (see, for example, Brave, Butters, and Justiniano (2019)). Being able to have both an early and accurate indication of its movements, therefore, has value to economic researchers. To demonstrate, we show how our short-term forecasts of UI claims during the Covid-19 pandemic can be incorporated into traditional macroeconomic forecasting models.

\section{Background on Forecasting UI Claims with Google Trends}

Forecasters have increasingly become aware of the value of the Google Trends data. For example, Choi and Varian (2012) show that searches on the topic of "unemployment" are capable of predicting turning points in US initial UI claims. ${ }^{7}$ A key limitation to Choi and Varian's analysis, however, is that Google searches on unemployment reflect a catch-all term for labor markets, including not only rising demand for unemployment insurance during downturns

\footnotetext{
${ }^{3}$ For examples of how firm level information can provide a leading indicator of construction spending and payroll employment, see Aaronson et al. (2016) and Cajner et al. (2019) respectively.

${ }^{4}$ https://trends.google.com/trends/?geo=US

${ }^{5}$ In this respect, our research design is similar to the "identification through heteroscedasticity" approach put forth in Rigobon (2003). The use of hurricanes as a source of identification is common in economics. See, for example, Gallagher and Hartley (2017), Deryugina (2017), Deryugina, Kawano, and Levitt (2018), and Ortega and Taspinar (2018).

${ }^{6}$ For example, it is included in the Conference Board's Leading Economic Index and is closely followed by financial markets to gauge future changes in payrolls and unemployment. See also Gordon (2009).

${ }^{7}$ Similar results are reported by D'Amuri and Marcucci (2017) for the US; McLaren and Shanbhogue (2011) for the UK; Askitas and Zimmermann (2009) for Germany; and Tuhkuri (2016) for Finland.
} 
but simultaneously potential news about future labor market conditions. This can lead the longrun association between initial UI claims and search intensity as measured by Google Trends to potentially be weak even if the two are very highly related during turning points in the business cycle. ${ }^{8}$ We overcome this limitation by looking at the variation in both initial UI claims and the Google Trends unemployment index around the landfall of hurricanes.

Hurricanes have a tremendous short-run effect on local economies, resulting in temporary surges in new UI claims among impacted areas. In the most extreme cases, new UI claims increase by as much as $300 \log$ points. They also generate a substantial spike in unemployment-related searches on Google. Because the hurricane induces search activity that is driven by demand for unemployment insurance (rather than news, for instance, about a labor market recovery), the relationship between initial UI claims and the Google Trends index around hurricane landfall can be used to more reliably calibrate models of the take-up for unemployment insurance.

Using a research design built on this premise described in section II, we show that the Google Trends unemployment topic index is highly predictive of subsequent unemployment insurance take-up after a hurricane's landfall. This is true in both an in-sample and out-of-sample sense, the latter of which is verified using a leave-one-out cross-validation procedure to quantify model uncertainty. Applying our elasticity estimates to state-level changes in the Google Trends indexes during the Covid-19 pandemic, we next show in section III that our model would have accurately predicted the historic surge in new UI claims for the US in March 2020. An extension of the Brave, Butters, and Justiniano (2019) real-time forecasting model, presented in section III, documents the impact that this historic surge in new UI claims is projected to have on US gross domestic product (GDP), payroll employment, and the unemployment rate.

\section{Data and Research Design}

The primary data used for our analysis is the initial claims of unemployment insurance of US states and territories and their Google Trends indexes measuring unemployment-related search histories. In figure 1, we display the time series of the aggregate versions of both of these variables over the time period from January 2004-March 2020.

Given our research design, we focus our analysis over a set of "event-windows" that encompass the top ten costliest hurricanes (in 2017 dollars), filtering on those that made landfall in the mainland US (NOAA, 2018; see table 1). This leaves us with seven hurricanes: Katrina in 2005, Harvey in 2017, Sandy in 2012, Irma in 2017, Ike in 2008, Wilma in 2005, and Rita in $2005 .{ }^{9}$

We build an event window for each hurricane that corresponds to the six months leading up to and following landfall. Then, for each hurricane, we identify the state most heavily affected and compare its Google search and initial unemployment insurance claim experience relative to the

\footnotetext{
${ }^{8}$ To the extent that there is measurement error in the Google Trends series, the estimated relationship might also be weak because of attenuation bias.

${ }^{9}$ The cost estimate of Hurricane Maria, which did not make it to the mainland US but affected Puerto Rico and neighboring islands, would make it the third costliest hurricane.
} 
nation as a whole. The most affected states are Louisiana for Katrina, Texas for Harvey, New Jersey for Sandy, Florida for Irma, Texas for Ike, Florida for Wilma, and Texas for Rita. Table 1 summarizes each of the events in our sample.

For each event, we gather the weekly Google Trends unemployment index for both the affected states as well as the country as a whole and the weekly initial unemployment insurance claims filed for both the affected state and the entire US. ${ }^{10}$ The Google Trends indexes provide a time series index of the volume of queries for a particular topic users enter into the Google search engine in a given geographic area. The index is based on the overall share a search term or topic makes up of the total number of searches over that time period for the region in question. Google Trends then standardizes the index such that the maximum of the time series is normalized to 100. In an effort to capture many possible alternative search terms and/or combinations that are all likely to be related to “unemployment,” we leverage Google Trends' "broad matched” unemployment "topic” index.

We measure the association between Google Trend search intensity and UI claims with the following equation:

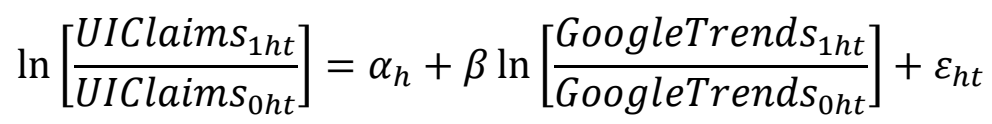

where $h$ indexes each of the 7 hurricane events, and $t$ indexes the weeks within the year-long window for each event. Because Google Trends search activity is reported almost in real-time, while UI claims are reported with a lag, the estimates from this model could be used directly as a means of "nowcasting" UI claims. ${ }^{11}$ We accommodate arbitrary seasonal and secular trends common across states by estimating the regression specification in terms of log-shares on logratios, where the subscript 1 references the affected state and the subscript 0 denotes our reference group, which in our baseline set of results will be the US as a whole. To accommodate differences in the average number of UI claims for the states of various population sizes across our events, we also include a set of event fixed-effects $\left(\alpha_{h}\right)$ in the above equation.

Hsu, Matsa, and Melzer (2018) document considerable heterogeneity across US states in the generosity of unemployment insurance. As generosity is likely to affect UI take-up, we also consider an alternative specification which instead matches each hurricane-affected state with the single US state that is simultaneously most like it in terms of UI generosity and the furthest from it in physical distance. The former ensures that take-up (and hence search activity) is likely to be similar in these states all else equal, while the latter ensures that the comparison state is not likely to suffer any major impact from the hurricane. In this instance of equation (1), the subscript 1

\footnotetext{
10 The initial unemployment insurance (UI) claims come from the FRED database maintained by the St. Louis FED and made publicly available at https://fred.stlouisfed.org/. For both the affected state and the US UI claims, we use non-seasonally adjusted data.

11 This process of predicting the present, or “nowcasting” as it was termed by Giannone, Reichlin, and Small (2008), has become an important part of the daily workflow of many private sector analysts and economic researchers.
} 
refers to the hurricane affected state and the subscript 0 refers to the comparison, or control state. The chosen comparison state best matching the criteria described above for each of the seven hurricanes is noted in table $1 .^{12}$ We also show that our research design is robust to a shorter-length event window, using (population) weighted regressions, and results in a null result for a "placebo" type event study. ${ }^{13}$

\section{Results}

Table 2 reports our estimates from equation (1). In our baseline specification (column 1), the estimated coefficient on the Google Trends measure is both large and positive, with an elasticity of 1.16 for initial UI claims, as well as precisely estimated, with a standard error (estimated from 10,000 event-level bootstrap and jackknife samples) of 0.20 . Given the precision of this estimate, we undertook an additional leave-one-out cross-validation of the regression to ensure that it was not overfit to a particular event. We report the estimates of the search elasticity from each of these additional specifications in columns 2-8 of table 2. The point estimates that resulted from this exercise were in the range of $[0.98,1.23]$, mostly in-line with the standard error of our overall estimate.

Using each leave-one-out estimate as the means to produce a one-week ahead forecast for each hurricane event in our sample, we are also able to provide an out-of-sample metric of the forecast accuracy of the model. Averaging across all of the events, the out-of-sample R-squared is 0.75.

To provide an assessment on the possibility that alternative explanations could have generated our results, we also conducted a series of robustness checks. To ensure our results are not contaminated by changes in state-level policies around the hurricane event, we ran our main regression specification under a more restrictive window of $+/-3$ months around the hurricane event (see, Table S1 in the supplementary materials). To explore the possibility that there might be some delay in how search results in UI claims, we also ran a version of the model with a lag of Google Trends intensity (see, Table S2 in the supplementary materials). To control for the possibility that overall UI generosity might be driving the results, we also conducted our main regression approach using a matched control state (see Table 1) as the reference group. Finally, we also ran a "placebo" test by assigning each hurricane event to an alternative state amongst our treated states that was unlikely to be impacted by the hurricane (e.g., New Jersey for Harvey; see, Table S4 in the supplementary materials), in addition to re-running our main specification with population weights (see, Table S5 in the supplementary materials).

In each case, we find only modest differences with our baseline. In particular, restricting to a shorter event window (1.23) and using population weights (1.01) each lead to modest changes in the point estimate, while using a state matched by UI generosity modestly lowers the point

\footnotetext{
12 The matching process is detailed in the supporting materials. To summarize, we rescaled the maximum UI benefit measure of Hsu, Matsa, and Melzer (2018) to be in standard deviation units from the cross-sectional average for our sample period in order to facilitate easily making comparisons across states on the dimension of UI generosity.

${ }^{13}$ For the "placebo" exercise, we assign each hurricane to one of the affected states in our study that is outside the region of the most affected state for that hurricane. We do this so as not to confound the multiple state effects of these hurricane events.
} 
estimates across the range of leave-one-out exercises [0.72, 1.06]. And, while there appears to be some scope for delayed effects in how search leads to unemployment insurance claims, the implied overall impact from this specification (i.e., the sum of coefficients) indicates a modest increase in the overall elasticity. Finally, across the range of placebo tests, one cannot reject the null of no effect. Combined, these tests suggest significant predictive power for the Google Trends measure in capturing variation in initial UI claims in the states affected by the landfall of the hurricanes in our sample.

Given the appealing features of our regression model in predicting initial UI claims over our set of seven major hurricane events, we next report what our estimates would imply for the number of UI claims during the early days of the Covid-19 pandemic. With several states implementing shelter-in-place policies of their residents and many businesses shutting down in March 2020, the resulting rise in UI claims was expected to be large-but how large was not clear. To this point, private sector forecasts for initial UI claims in the early days of the pandemic using a variety of methods (including aggregating recent news report accounts) ranged from as low as 1 to as much as 4 million for the week ending March 21, 2020 (e.g., Yglesias, M. (2020)).

Figure 3 reports our model estimates of initial UI claims on a non-seasonally adjusted basis for the weeks ending March 21, 2020 and March 28, 2020 - which were subsequently reported at 8:30am (EST) on March 26, 2020 and April 2, 2020. While considerable variation exists across the individual states, across-the-board the model forecasts substantial increases in initial UI claims that would make it the largest single and two-week increases in US history. The model's forecasts (of log-changes) are also well calibrated in both weeks. ${ }^{14}$ In both weeks, $80 \%$ of states fall within their 95\% confidence prediction interval, with several of the states falling outside in both instances, but in opposite directions (e.g. California) — a further indication of some delay in the resulting claims from search (see Table S2 in the supplementary materials).

Using our point estimate from the baseline regression, we forecasted initial UI claims for the US as a whole to be 2.9 million (Panel A), with a 95\% prediction interval of 1.0 to 4.6 million, for the week ending March 21, 2020. The advance (and ultimately, final) release of initial UI claims was 2.9 million for the week ending March 21, falling on top of our estimates. Our projection for the week of March 28, 2020 predicted that new UI claims for the US as a whole would be between 4.2 and 6.0 million, with a mean prediction of 5.0 million (Panel B). ${ }^{15}$ The advance report of UI Claims for the week ending March 28, 2020 came in at 5.8 million. It is important to note that these forecasts represent an out-of-sample prediction, as opposed to some of the other recent approaches that have used early reports from individual states as the basis for the aggregate forecast (e.g. Sojourner and Goldsmith-Pinkham, 2020). ${ }^{16}$

\footnotetext{
${ }^{14}$ In a cross sectional regression of log actual changes in UI claims on the predicted log change, we cannot reject the joint null hypothesis that the constant is zero and the coefficient on the predicted changes is one at the $1 \%$ significance level, for either week.

${ }^{15}$ To obtain a prediction for the week of March 28, 2020, we used the two weeks of Google Trends data following March 7, 2020 along with that week's initial unemployment insurance (UI) claims number.

${ }^{16}$ A version of the Choi and Varian (2012) model estimated on data from 2014-2019 predicts UI claims to be 267 thousand and 1.7 million (non-seasonally adjusted basis) for the weeks ending March 21, 2020 and March 28, 2020, respectively. In contrast, the additional information in the early state reports led the Sojourner and Goldsmith-
} 
To obtain an estimate of the broader labor market effects of the pandemic, we take our initial UI claims predictions for the last two weeks of March and combine them with the results for the first two weeks of March to arrive at a March estimate of monthly initial UI claims. Then, we "plug" this estimate into the real-time data flow as of March 30, 2020 for an extended version of the Brave, Butters, and Justiniano (2019) mixed-frequency BVAR (MF-BVAR) model of US economic activity. ${ }^{17}$ The historic surge in new UI claims in March 2020 predicted by our model is interpreted as a highly negative shock to economic activity in the MF-BVAR. Figure 4 compares the model forecasts with versus without our UI claims plug; the level of GDP is 13\% lower (blue bar), payrolls are $11 \%$ lower (red bar), and the unemployment rate is 7.6 percentage points higher (gray bar) by the first quarter of 2021 when our plug is included. All three results represent substantial informational gains not found in the existing real-time data flow.

\section{Conclusion}

The Covid-19 pandemic is likely to test the limits of usefulness of traditional economic data and statistical models. The sheer magnitude of the shock to labor market activity is unprecedented in recent history. However, we have shown that recently developed high frequency "big data" sources like Google Trends can be useful predictors of labor market conditions even in such a very uncertain environment. Furthermore, while other methods used to-date to predict initial UI claims with this data in the current environment have relied primarily on the early reporting of results by states, our method is robust to the possibility that such reporting may at some point no longer be possible or feasible. This is made possible by the precision of our estimates afforded by studying past responses of UI claims and Google searches to hurricane landfalls in the US.

The correlation of initial UI claims and Google Trends searches for unemployment for U.S. states affected by the landfall of hurricanes appears to share very similar characteristics to the labor market response to the current pandemic. Hurricanes, however, are by their very nature localized events whose impacts are limited based on a state's exposure to coastal areas. Covid-19 does not respect geographical boundaries. One potential risk of using our approach in the current environment is if the Google search behavior of users is radically different in local and national natural disasters. Furthermore, anecdotal reports suggest that the magnitude of the shock may also be impacting a person's actual ability to file a UI claim as well as his or her state's ability to process it, which could alter the timing of the relationship we identify (e.g. make it more lagged as opposed to contemporaneous).

Pinkham (2020)'s model to predict UI claims to be 3.8 and 4.7 million (non-seasonally adjusted) for the same weeks.

17 This version of the MF-BVAR contains 107 monthly and quarterly time series for US real economic activity, many of which are used by the Bureau of Economic Analysis as source data for US gross domestic product. 


\section{References}

Aaronson, D. and S. Brave, and R. Cole, (2016), “Using Private Sector `Big Data’ as an Economic Indicator: The Case of Construction Spending,” Chicago Fed Letter. No. 366.

Askitas, N. and Zimmermann, K. F. (2009), “Google Econometrics and Unemployment Forecasting,” Applied Economics Quarterly, 55(2), 107-120

Brave, Scott A and R. Andrew Butters and Alejandro Justiniano (2019). "Forecasting economic activity with mixed frequency BVARs.” International Journal of Forecasting. Vol. 35, No. 4.

Cajner, T. and L. Crane, and, R. Decker, and A. Hamins-Puertolas, and C. Kurz, "Tracking the Labor Market with 'Big Data’,” FEDS Notes, September 20, 2019.

Choi, H. and Varian, H. (2012), "Predicting the Present with Google Trends.” Economic Record, 88: 2-9. doi:10.1111/j.1475-4932.2012.00809.x

D’Amuri, F. and Marcucci, J. (2017), “The Predictive Power of Google Searches in Forecasting Unemployment,” International Journal of Forecasting, 33: 801-816.

Deryugina, Tatyana (2017), “The Fiscal Cost of Hurricanes: Disaster Aid versus Social Insurance,” AEJ: Economic Policy, Vol. 9, No. 3.

Deryugina, Tatyana and Laura Kawano and Steven Levitt (2018), “The Economic Impact of Hurricane Katrina on Its Victims: Evidence from Individual Tax Returns,” AEJ: Applied Economics, Vol. 10, No. 2

Gallagher, Justin and Daniel Hartley (2017), "Household Finance after a Natural Disaster: The Case of Hurricane Katrina,” AEJ: Economic Policy, Vol. 9, No. 3.

Giannone, D. and L. Reichlin and D. Small (2008). "Nowcasting: The real-time information content of macroeconomic data,” Journal of Monetary Economics. Vol. 55, No. 4.

Gordon, Robert (2009). "Green shoot or dead twig: Can unemployment claims predict the end of the American recession?” Vox. Date accessed: 3/23/2020. https://voxeu.org/article/us-recoverymay-2009-new-evidence-based-surprisingly-robust-linkage

Hsu, J.W. and D.A. Matsa and B.T. Melzer (2018). “Unemployment Insurance as a Housing Market Stabilizer,” American Economic Review. Vol. 108, No. 1.

McLaren, N. and Shanbhogue, R. (2011), "Using internet search data as economic indicators,” Bank of England Quarterly Bulletin, 1: 134-140.

Ortega, F. and S. Taspinar (2018), "Rising sea levels and sinking property values: Hurricane Sandy and New York’s housing market,” Journal of Urban Economics, Vol. 106

Rigobon, R. (2003). “Identification through heteroscedasticity,” Review of Economics and Statistics, Vol. 85, No. 4. 
Sojourner and Goldsmith-Pinkham (2020). "The Coronavirus crisis led to a record-breaking spike in weekly unemployment insurance claims.” Economic Policy Institute, Working Economics Blog, March 23, 2020. https://www.epi.org/blog/coronavirus-record-breaking-spikein-ui-claims/

Suhoy (2009). “Query Indices and 2008 Downturn: Israeli Data,” Bank of Israel Discussion Paper.

Tuhkuri, Joonas (2016). “Forecasting unemployment with Google searches.” ETLA.Working Paper No. 35.

Yglesias, M. (2020), "The unprecedented tsunami of unemployment insurance claims, explained.” Vox. Date accessed: 3/22/2020. https://www.vox.com/2020/3/21/21188529/initialunemployment-claims-goldman-sachs 


\section{Table 1. Summary of Hurricane Events}

\begin{tabular}{|c|c|c|c|c|c|c|}
\hline Event & Damage (2017 dollars) & Event Date Affected State & Control State & Placebo State & Start Window & End Window \\
\hline Hurricane Katrina & $160 B$ & 8/27/2005 Louisiana & Arizona & New Jersey & $2 / 1 / 2005$ & $2 / 1 / 2006$ \\
\hline Hurricane Harvey & $125 B$ & 8/25/2017 Texas & Michigan & New Jersey & $2 / 1 / 2017$ & $2 / 1 / 2018$ \\
\hline Hurricane Maria & $90 \mathrm{~B}$ & 9/23/2017 - & - & - & - & - \\
\hline Hurricane Sandy & $70 B$ & 10/29/2012 New Jersey & Washington & Texas & $4 / 1 / 2012$ & $4 / 1 / 2013$ \\
\hline Hurricane Irma & $50 B$ & 9/7/2017 Florida & Missouri & New Jersey & $3 / 1 / 2017$ & $3 / 1 / 2018$ \\
\hline Hurricane Andrew & $48 \mathrm{~B}$ & 8/23/1992 - & - & - & - & - \\
\hline Hurricane Ike & $34 B$ & 9/7/2008 Texas & Michigan & New Jersey & $3 / 1 / 2008$ & $3 / 1 / 2009$ \\
\hline Hurricane Ivan & $27 \mathrm{~B}$ & $9 / 13 / 2004-$ & - & - & - & - \\
\hline Hurricane Wilma & $24 B$ & 10/25/2005 Florida & Missouri & New Jersey & $4 / 1 / 2005$ & $4 / 1 / 2006$ \\
\hline Hurricane Rita & $23 \mathrm{~B}$ & 9/25/2005 Texas & Michigan & New Jersey & $3 / 1 / 2005$ & $3 / 1 / 2006$ \\
\hline
\end{tabular}

Note: This table summarizes the top ten hurricanes used in our event study analysis, including the approximate midpoint of each hurricane's duration, the affected state used for each event, the matched control state with a comparable UI system, the placebo state, and the +/- 6 month window that comprises the event window. Of the top ten hurricanes, Maria, Andrew, and Ivan were excluded from our analysis because they either did not hit the mainland US or occurred before Google Trends data was available.

Table 2. Event Study Regression Results

\begin{tabular}{lrrrrrrrr}
\hline \hline & $(1)$ & \multicolumn{1}{c}{$(2)$} & $(3)$ & \multicolumn{1}{c}{$(4)$} & \multicolumn{1}{c}{$(5)$} & \multicolumn{1}{c}{$(6)$} & \multicolumn{1}{c}{$(7)$} & \multicolumn{1}{c}{$(8)$} \\
\hline Google Trends Ratio & 1.162 & 0.982 & 1.124 & 1.143 & 1.144 & 1.237 & 1.156 & 1.231 \\
& $(0.201)$ & $(0.252)$ & $(0.136)$ & $(0.346)$ & $(0.330)$ & $(0.076)$ & $(0.150)$ & $(0.138)$ \\
& & & & & & & & \\
Left Out Event & & Katrina & Harvey & Sandy & Irma & Wilma & Ike & Rita \\
Adj. R-squared & 0.509 & 0.309 & 0.488 & 0.516 & 0.495 & 0.554 & 0.523 & 0.558 \\
Num. Observations & 366 & 314 & 314 & 313 & 314 & 314 & 313 & 314 \\
\hline \hline
\end{tabular}

Note: This table reports regression results for equation (1), where we report the coefficient on the Google Trends Ratio term and its standard error, estimated by 10,000 event-level bootstrap and jackknife samples, in parentheses. In column (1), we report estimates using all of the hurricane events; and in each subsequent column, we report results from leaving each of the seven hurricane events out individually. 
Figure 1. Initial Claims and Google Trends of Unemployment Searches

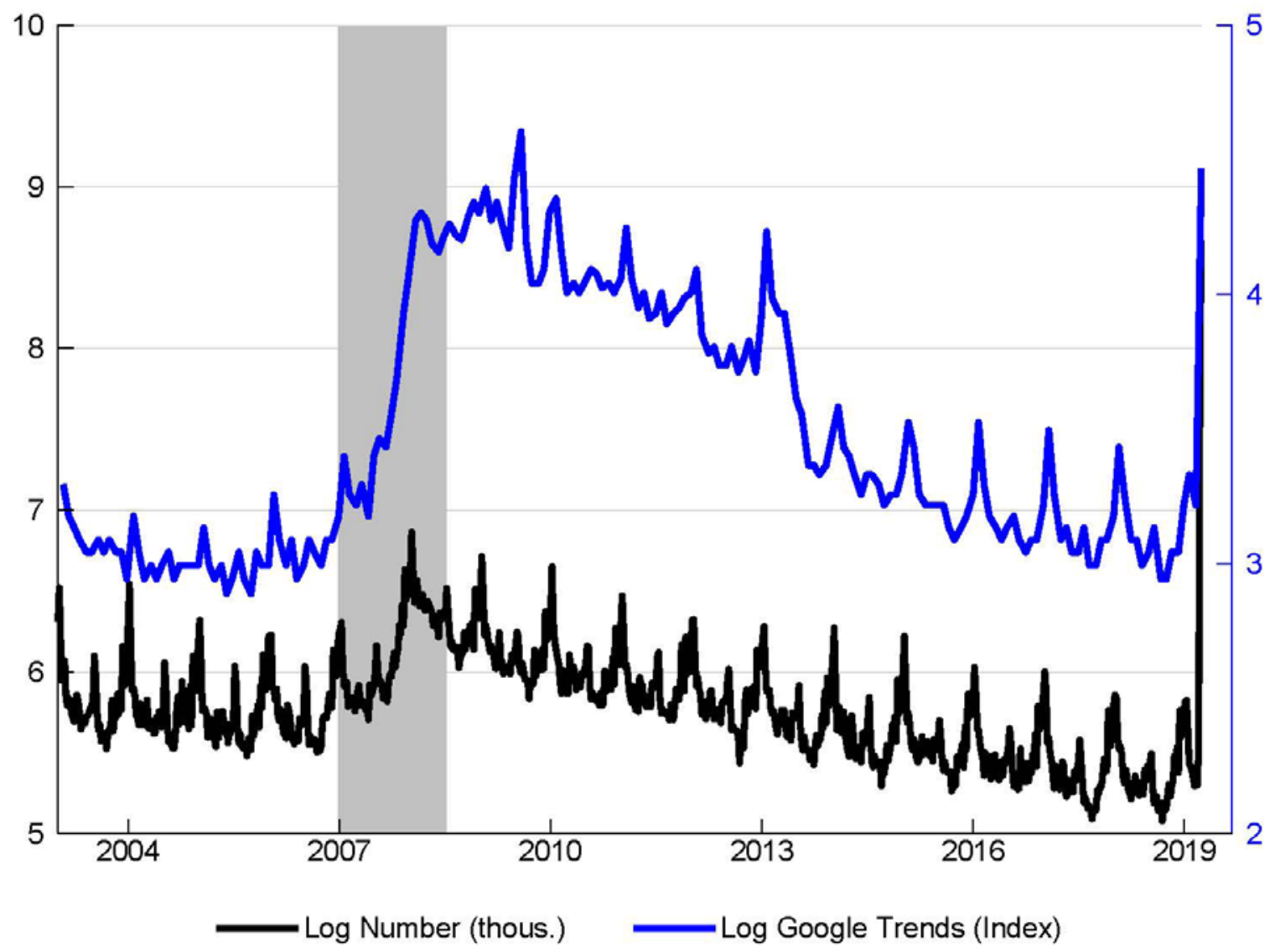

Note: This figure displays the time series of initial unemployment insurance claims (black, non-seasonally adjusted (nsa)) and the Google Trends index (blue, nsa) for the "unemployment" topic over the time period of January 2004 to March 2020. US recessions currently defined by the National Bureau of Economic Research are shaded in gray. 
Figure 2. Selected Hurricane Event Studies
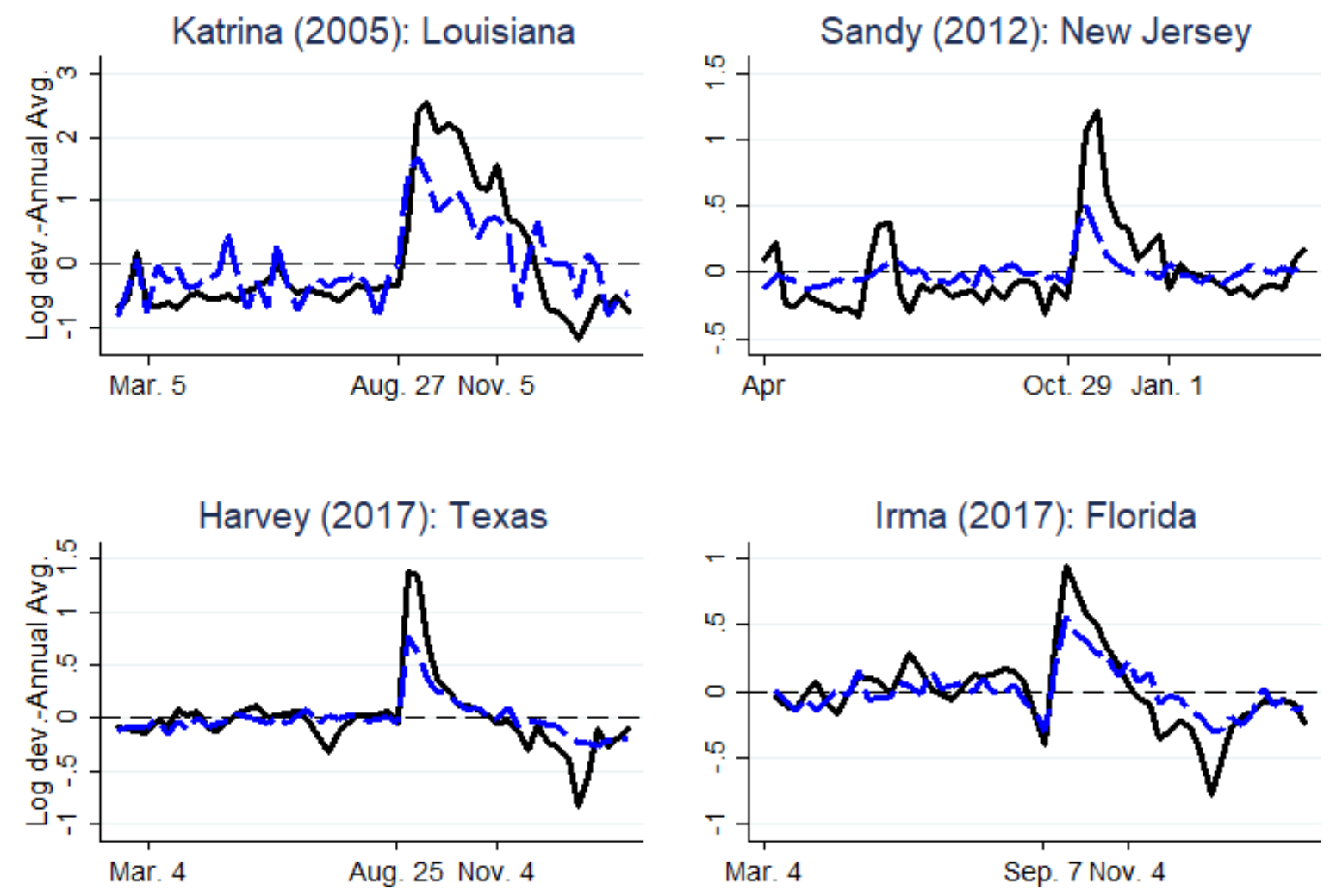

Note: This figure displays the time series of the log share of initial unemployment insurance claims (black line) and the log ratio of the Google Trends measure (blue dashed line) for the "unemployment" topic less the annual average for the six months leading up to and following the landfall of each of our top four hurricane event studies. 


\section{Figure 3. State and National Initial Unemployment Insurance Claims}

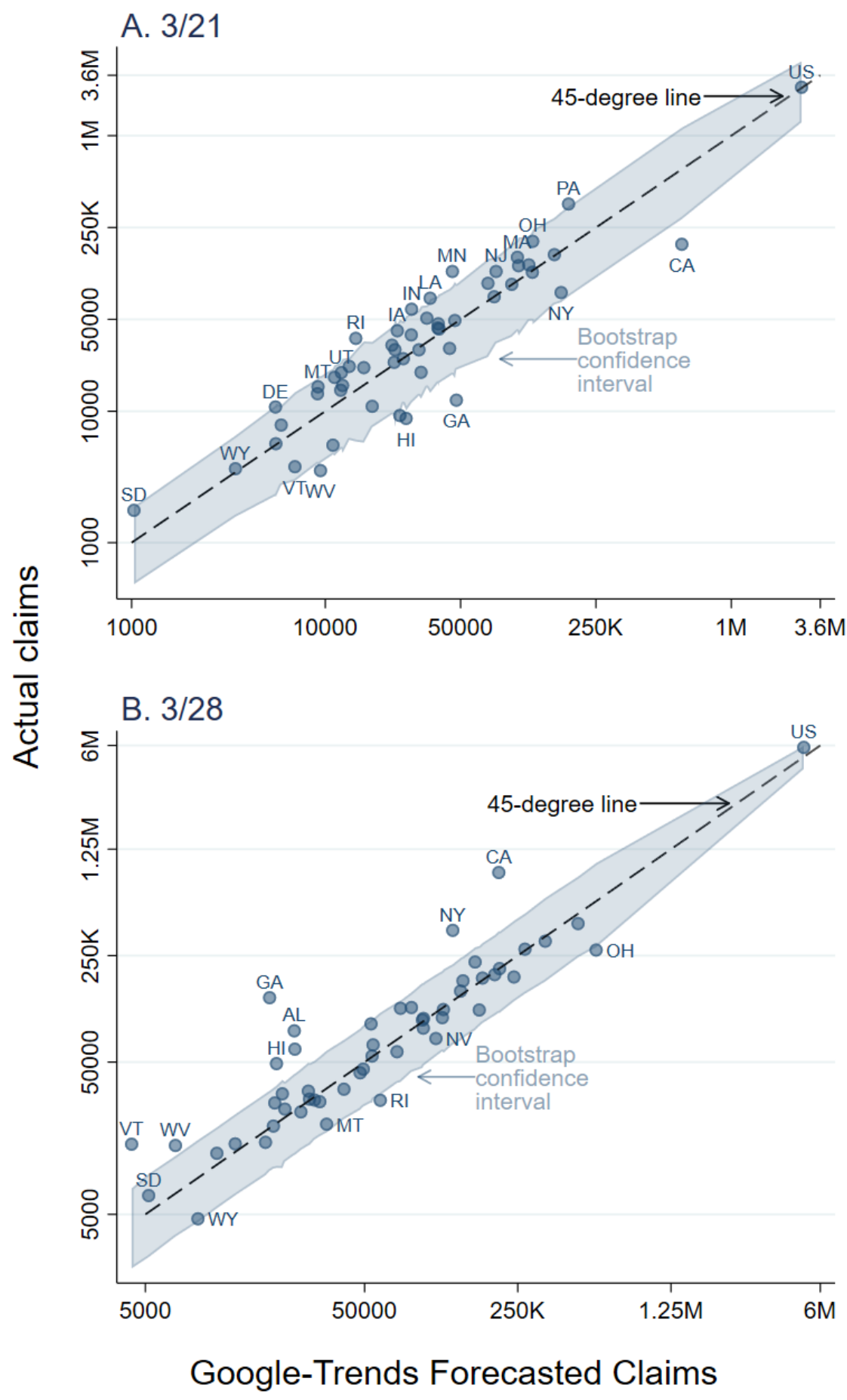

Note: This figure reports the forecasted values for each state from our model using Google Trends, as well as the reported initial unemployment insurance claims (final) number for the week ending March 21, 2020 (panel A) and the (advance) number for the week ending March 28, 2020. The interpolated 95\% confidence interval is also reported based on 10,000 event-level bootstrap and jackknife samples. 
Figure 4: Impact of March 2020 Initial UI Claims on Projections of Economic Activity

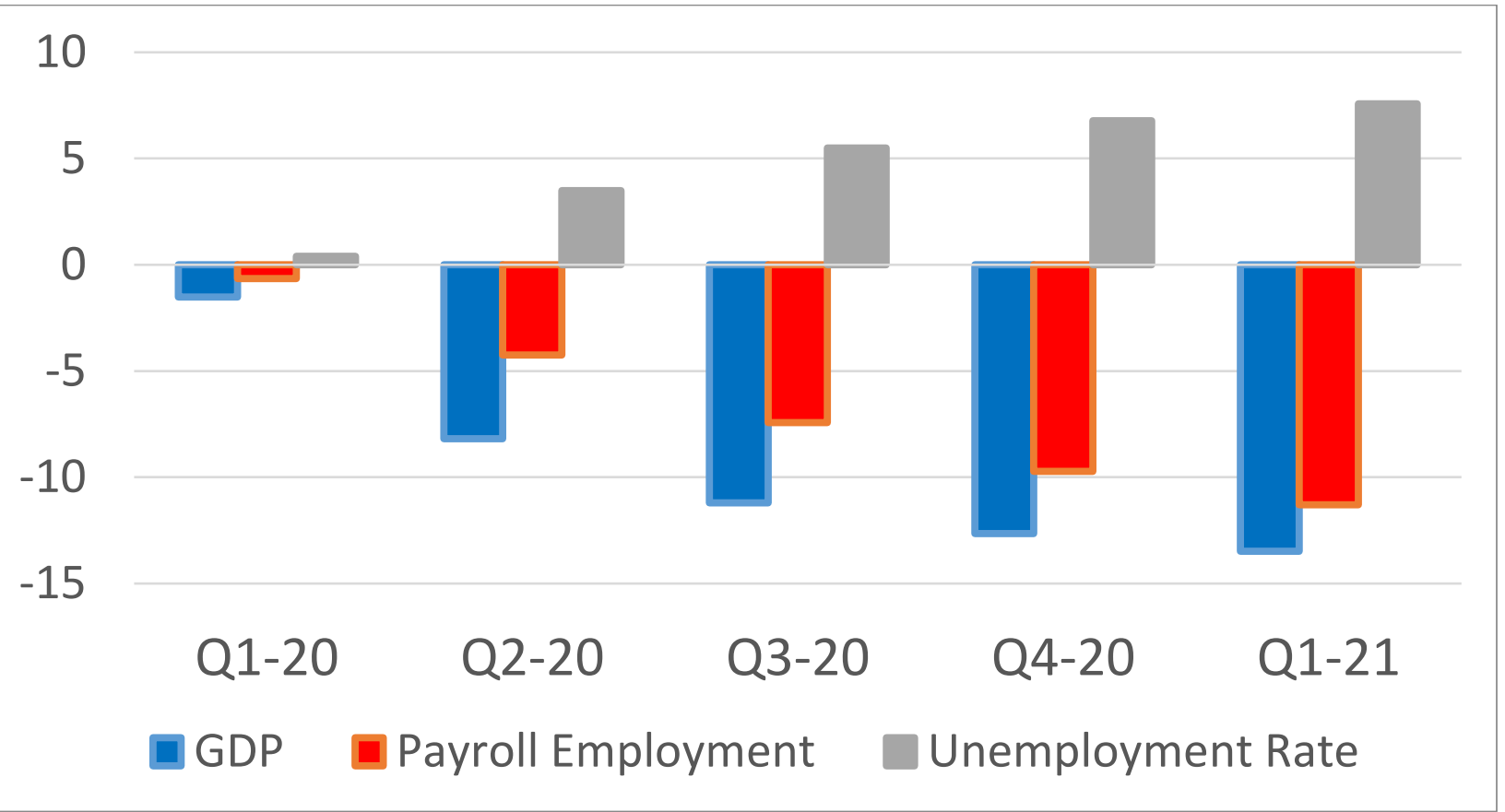

Note: This figure displays the percentage difference (or percentage point difference for the unemployment rate) in each quarter between the projections for the level of U.S. real GDP, payroll employment, and the unemployment rate with and without our estimates of March 2020 initial UI claims using data available as of March 30, 2020 from a 107-variable version of the Brave, Butters, Justiniano (2019) mixed-frequency BVAR mode of US economic activity. 
Supporting Materials

Table S1: Three Month Window Event Study Regression Results

\begin{tabular}{lrrrrrrrr}
\hline \hline & $(1)$ & $(2)$ & $(3)$ & \multicolumn{1}{c}{$(4)$} & \multicolumn{1}{c}{$(5)$} & \multicolumn{1}{c}{$(6)$} & \multicolumn{1}{c}{$(7)$} & \multicolumn{1}{c}{$(8)$} \\
\hline Google Trends Ratio & 1.232 & 1.207 & 1.191 & 1.209 & 1.202 & 1.283 & 1.219 & 1.295 \\
& $(0.192)$ & $(0.289)$ & $(0.168)$ & $(0.215)$ & $(0.346)$ & $(0.268)$ & $(0.197)$ & $(0.070)$ \\
& & & & & & & & \\
Left Out Event & & Katrina & Harvey & Sandy & Irma & Wilma & Ike & Rita \\
Adj. R-squared & 0.545 & 0.371 & 0.523 & 0.550 & 0.526 & 0.580 & 0.565 & 0.604 \\
Num. Observations & 203 & 174 & 174 & 174 & 174 & 174 & 174 & 174 \\
\hline \hline
\end{tabular}

Note: This table reports results for equation (1) using a +/-3 month window around the hurricane event. We report the coefficient on the Google Trends Ratio term and its standard error, estimated by 10,000 event-level bootstrap and jackknife samples, in parentheses. In column (1), we report estimates using all of the hurricane events; and in each subsequent column, we report results from leaving each of the seven hurricane events out individually.

Table S2: Allowing for Delayed Claims in Event Study Regression Results

\begin{tabular}{lrrrrrrrr}
\hline \hline & \multicolumn{1}{c}{$(1)$} & \multicolumn{1}{c}{$(2)$} & \multicolumn{1}{c}{$(3)$} & \multicolumn{1}{c}{$(4)$} & \multicolumn{1}{c}{$(5)$} & \multicolumn{1}{c}{$(6)$} & \multicolumn{1}{c}{$(7)$} & \multicolumn{1}{c}{$(8)$} \\
\hline Google Trends Ratio & 0.793 & 0.767 & 0.747 & 0.783 & 0.768 & 0.847 & 0.787 & 0.833 \\
& $(0.116)$ & $(0.306)$ & $(0.051)$ & $(0.060)$ & $(0.179)$ & $(0.166)$ & $(0.143)$ & $(0.190)$ \\
& & & & & & & & \\
Google Trends Ratio (t-1) & 0.639 & 0.492 & 0.659 & 0.622 & 0.659 & 0.637 & 0.635 & 0.669 \\
& $(0.096)$ & $(0.096)$ & $(0.059)$ & $(0.091)$ & $(0.105)$ & $(0.137)$ & $(0.101)$ & $(0.122)$ \\
& & & & & & & & \\
Left Out Event & & Katrina & Harvey & Sandy & Irma & Wilma & Ike & Rita \\
Sum of Coef. & 1.43 & 1.26 & 1.41 & 1.40 & 1.43 & 1.48 & 1.42 & 1.50 \\
SE & 0.20 & 0.30 & 0.11 & 0.06 & 0.22 & 0.24 & 0.10 & 0.09 \\
Adj. R-squared & 0.61 & 0.38 & 0.60 & 0.62 & 0.61 & 0.64 & 0.63 & 0.67 \\
Num. Observations & 359 & 308 & 308 & 307 & 308 & 308 & 307 & 308 \\
\hline \hline
\end{tabular}

Note: This table reports results from an alternative to our baseline specification where an additional lag of the Google Trends Ratio is included in the model. We report the coefficient on the contemporaneous and lagged value of the Google Trends Ratio term and their standard errors, estimated by 10,000 event-level bootstrap and jackknife samples, in parentheses. In column (1), we report estimates using all of the hurricane events; and in each subsequent column, we report results from leaving each of the seven hurricane events out individually. The sum of the lag coefficients and its associated standard error is reported for each specification as well. 
Table S3: Alternative Control State Event Study Regression Results

\begin{tabular}{lrrrrrrrr}
\hline \hline & \multicolumn{1}{c}{$(1)$} & \multicolumn{1}{c}{$(2)$} & \multicolumn{1}{c}{$(3)$} & \multicolumn{1}{c}{$(4)$} & \multicolumn{1}{c}{$(5)$} & \multicolumn{1}{c}{$(6)$} & \multicolumn{1}{c}{$(7)$} & \multicolumn{1}{c}{$(8)$} \\
\hline Google Trends Ratio & 0.915 & 0.720 & 0.862 & 0.904 & 0.903 & 1.066 & 0.902 & 0.972 \\
& $(0.204)$ & $(0.339)$ & $(0.118)$ & $(0.196)$ & $(0.323)$ & $(0.257)$ & $(0.174)$ & $(0.218)$ \\
& & & & & & & & \\
Left Out Event & & Katrina & Harvey & Sandy & Irma & Wilma & Ike & Rita \\
Adj. R-squared & 0.375 & 0.213 & 0.355 & 0.376 & 0.377 & 0.450 & 0.382 & 0.418 \\
Num. Observations & 366 & 314 & 314 & 313 & 314 & 314 & 313 & 314 \\
\hline \hline
\end{tabular}

Note: This table reports results from an alternative to the baseline model that uses a control state matched by unemployment insurance generosity as the reference category for each hurricane event. We report the coefficient on the Google Trends Ratio term and its standard error, estimated by 10,000 event-level bootstrap and jackknife samples, in parentheses. In column (1), we report estimates using all of the hurricane events; and in each subsequent column, we report results from leaving each of the seven hurricane events out individually.

Table S4: Placebo Event Study Regression Results

\begin{tabular}{lrrrrrrrr}
\hline \hline & \multicolumn{1}{c}{$(1)$} & \multicolumn{1}{c}{$(2)$} & \multicolumn{1}{c}{$(3)$} & \multicolumn{1}{c}{$(4)$} & \multicolumn{1}{c}{$(5)$} & \multicolumn{1}{c}{$(6)$} & \multicolumn{1}{c}{$(7)$} & \multicolumn{1}{c}{$(8)$} \\
\hline Google Trends Ratio & 0.075 & 0.117 & 0.059 & 0.037 & 0.055 & 0.105 & 0.090 & 0.084 \\
& $(0.086)$ & $(0.061)$ & $(0.026)$ & $(0.052)$ & $(0.031)$ & $(0.147)$ & $(0.098)$ & $(0.104)$ \\
& & & & & & & & \\
Left Out Event & & Katrina & Harvey & Sandy & Irma & Wilma & Ike & Rita \\
Adj. R-squared & -0.014 & -0.009 & -0.016 & -0.018 & -0.016 & -0.011 & -0.011 & -0.013 \\
Num. Observations & 366 & 314 & 314 & 313 & 314 & 314 & 313 & 314 \\
\hline \hline
\end{tabular}

Note: This table reports results from an alternative to the baseline model that uses a "placebo" state as the primary treated state (see Table 1). We report the coefficient on the Google Trends Ratio term and its standard error, estimated by 10,000 event-level bootstrap and jackknife samples, in parentheses. In column (1), we report estimates using all of the hurricane events; and in each subsequent column, we report results from leaving each of the seven hurricane events out individually.

\section{Table S5: Population Weighted Event Study Regression Results}

\begin{tabular}{|c|c|c|c|c|c|c|c|c|}
\hline & $(1)$ & (2) & (3) & (4) & (5) & (6) & (7) & (8) \\
\hline \multirow[t]{2}{*}{ Google Trends Ratio } & 1.036 & 0.949 & 0.898 & 1.024 & 0.982 & 1.190 & 1.026 & 1.221 \\
\hline & $(0.261)$ & $(0.354)$ & $(0.267)$ & $(0.263)$ & $(0.290)$ & $(0.247)$ & $(0.264)$ & $(0.224)$ \\
\hline Left Out Event & & Katrina & Harvey & Sandy & Irma & Wilma & Ike & Sita \\
\hline Adj. R-squared & 0.39 & 0.31 & 0.32 & 0.40 & 0.35 & 0.48 & 0.42 & 0.51 \\
\hline Num. Observations & 366 & 314 & 314 & 313 & 314 & 314 & 313 & 314 \\
\hline
\end{tabular}

Note: This table reports results from a weighted version of the baseline model where weights are based on population. We report the coefficient on the Google Trends Ratio term and its standard error clustered at the event in parentheses. In column (1), we report estimates using all of the hurricane events; and in each subsequent column, we report the results from leaving each of the seven hurricane events out individually. 


\section{Figure S1: Matching on State Unemployment Insurance Generosity}

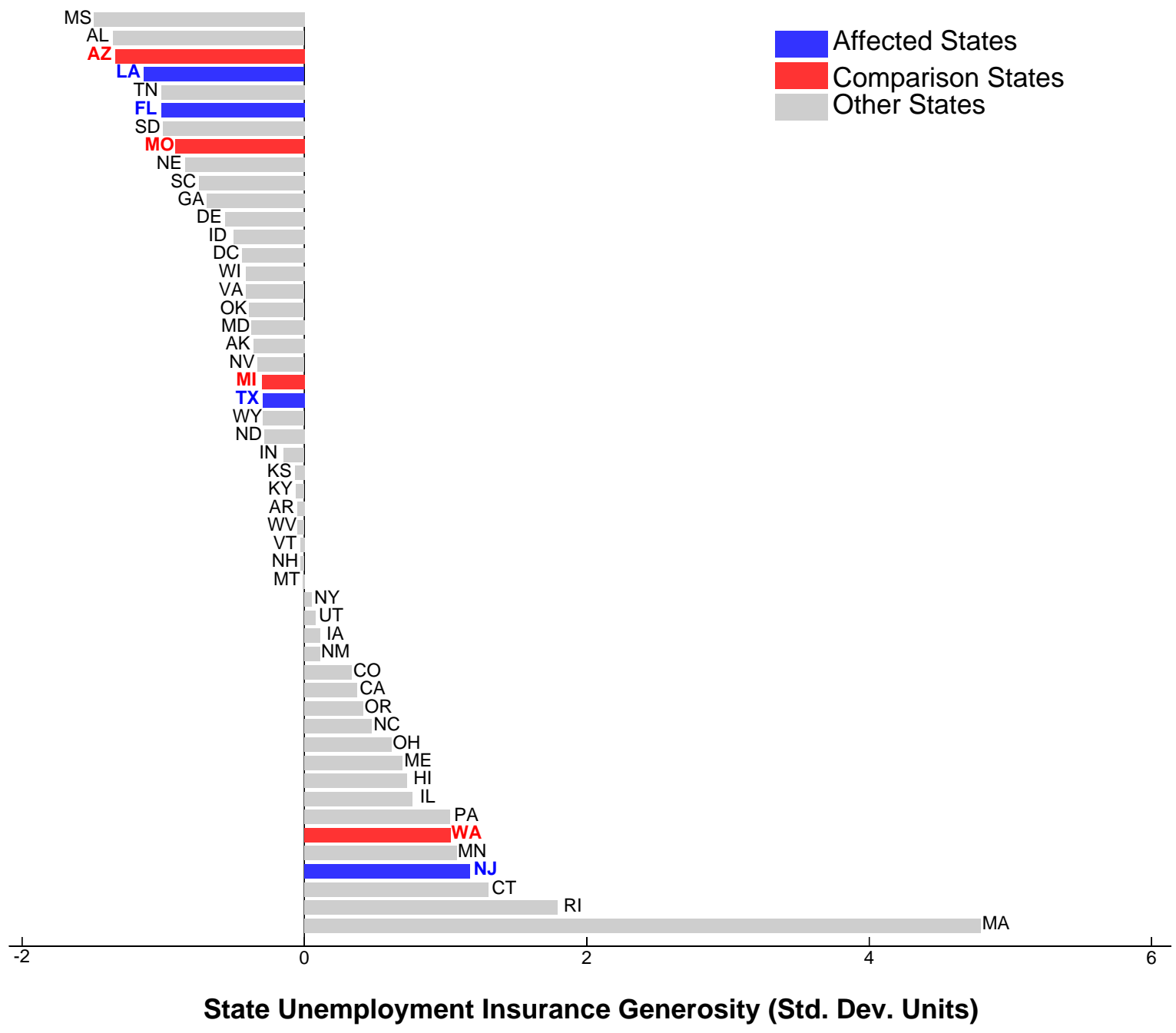

Note: This figure displays the 2004-2010 sample average of the Hsu, Matsa, and Melzer (2018) maximum benefit variable used to measure unemployment insurance generosity by state, measured in standard deviation units from the cross-sectional average. The states affected by hurricanes in our analysis are shaded in blue, and the matched control states are shaded in red. See table 1 for further details. 
Figure S2. Initial Unemployment Insurance Claim Shares and Relative Google Trends

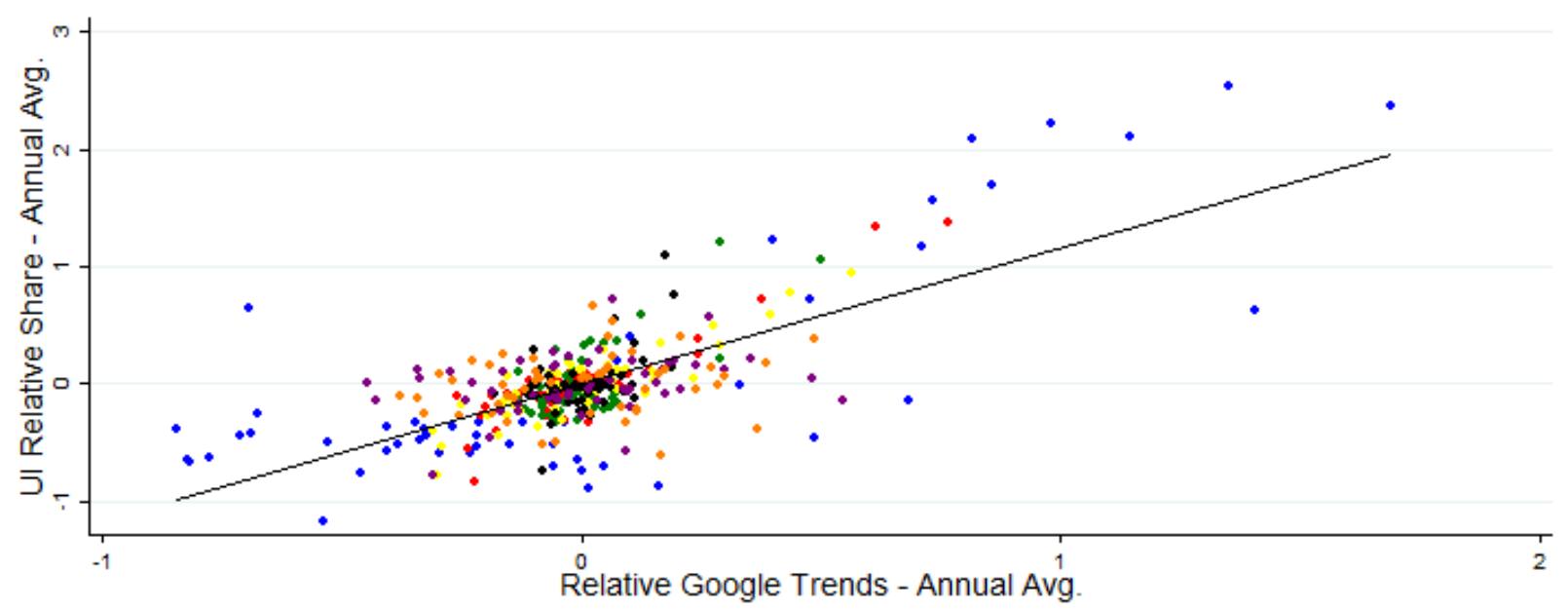

Note: This figure displays the log share of initial unemployment insurance claims versus the log ratio of Google Trends for the "unemployment" topic for the seven hurricane-affected states relative to the US: Katrina (Louisiana, in blue), Harvey (Texas, in red), Sandy (New Jersey, in green), Irma (Florida, in yellow), Ike (Texas, in black), Wilma (Florida, in purple), and Rita (Texas, in orange). 